\title{
ADMM-Based Distributed Optimal Reactive Power Control for Loss Minimization of DFIG-Based Wind Farms
}

\author{
Huang, Sheng; Li, Peiyao ; Wu, Qiuwei; Li, Fangxing ; Rong, Fei
}

Published in:

International Journal of Electrical Power \& Energy Systems

Link to article, DOI:

10.1016/j.ijepes.2020.105827

Publication date:

2020

Document Version

Peer reviewed version

Link back to DTU Orbit

Citation $(A P A)$ :

Huang, S., Li, P., Wu, Q., Li, F., \& Rong, F. (2020). ADMM-Based Distributed Optimal Reactive Power Control for Loss Minimization of DFIG-Based Wind Farms. International Journal of Electrical Power \& Energy Systems, 118, [105827]. https://doi.org/10.1016/j.ijepes.2020.105827

\section{General rights}

Copyright and moral rights for the publications made accessible in the public portal are retained by the authors and/or other copyright owners and it is a condition of accessing publications that users recognise and abide by the legal requirements associated with these rights.

- Users may download and print one copy of any publication from the public portal for the purpose of private study or research.

- You may not further distribute the material or use it for any profit-making activity or commercial gain

- You may freely distribute the URL identifying the publication in the public portal 


\title{
ADMM-Based Distributed Optimal Reactive Power Control for
}

\section{Loss Minimization of DFIG-Based Wind Farms}

\author{
Sheng Huang ${ }^{\mathrm{a}}$, Peiyao $\mathrm{Li}^{\mathrm{b}}$, Qiuwei $\mathrm{Wu}^{\mathrm{a}, *}$, Fangxing $\mathrm{Li}^{\mathrm{c}}$, Fei Rong ${ }^{\mathrm{b}}$ \\ ${ }^{a}$ Center for Electric Power and Energy (CEE), Department of Electrical Engineering, Technical University of Denmark (DTU), Kgs. Lyngby, 2800, Denmark \\ ${ }^{\mathrm{b}}$ College of Electrical and Information Engineering, Hunan University, Changsha 410082, China \\ ${ }^{c}$ Department of Electrical Engineering and Computer Science, University of Tennessee, Knoxville TN 37996, USA
}

\begin{abstract}
In this paper, a distributed optimal reactive power control (DORPC) scheme is proposed for minimizing the total losses of doubly fed induction generator (DFIG)-based wind farms (WFs), including the losses of generators, converters, filters, and networks. The DORPC minimizes total WF losses by optimally coordinating reactive power outputs of the DFIG stator and the grid-side converter. The optimal control problem is solved in a distributed manner by using the consensus alternating direction method of multipliers (ADMM). With the consensus ADMM, the total WF loss optimization problem is transformed into a distributed optimal power flow problem considered with DFIGs' optimal operation. The optimization problem with local constraints considers the reactive power limit of DFIG-based wind turbines (WTs) and the voltage limits at all WT terminal buses inside the WF. In the DORPC, the optimal control problem is solved by the collector bus station controller and WT controllers in parallel, only with the information exchange between immediate neighbors. It eliminates the need of a central controller and centralized communication, implying better robustness and plug-and-play capability. A WF with 20 DFIG-based WTs was used to validate the proposed DORPC scheme.
\end{abstract}

\section{Keywords}

Alternating direction method of multipliers (ADMM), distributed reactive power control, doubly fed induction generator (DFIG), loss minimization, wind farm.

\section{Introduction}

Wind power has become a widely used renewable energy source (RES) with substantial potential and mature technology. With wind power generation expanding, the intermittency of wind power and the interaction between wind farms (WFs) and power systems introduce challenges [1]. The doubly fed induction generator (DFIG)-based wind turbine (WT) has been widely used in modern WFs due to high controllability and small converter rating [2]. With power electronic converters, DFIG-based WFs can regulate reactive power independently and provide reactive power support for power systems [3].

Voltage and reactive power control of WFs has motivated numerous studies. The WF is required to maintain the power factor within the limit at the point of connection (POC) [4], [5] or provide reactive power support for power systems while tracking the dispatch command from the transmission system operator (TSO) [6]. Dynamic power electronic devices, such as static var compensators (SVC) and static synchronous compensators (STATCOM), are used in WFs for providing rapid reactive compensation and voltage control [7], [8]. In DFIG-based WFs, each DFIG-based WT is equipped with power electronic converters. The DFIG-based WF can utilize the capabilities of the DFIG-based WTs for providing reactive power support to meet grid code requirements.

\footnotetext{
*Corresponding author.

E-mail addresses: qw@elektro.dtu.dk (Q.Wu).
} 
The most widely used reactive power control scheme in WFs is the proportional dispatch (PD) scheme, which is simple, easy to implement, and considers the reactive power margin of each DFIG-based WT [9], [10]. However, without the optimizing reactive power references for individual WTs, the WF controller cannot achieve WF optimal operation. In [11], the particle swarm optimization (PSO) was adopted to dispatch reactive power of WTs by minimizing total active power losses along the cables and the transformers of WTs. In [12], the objectives of the optimal control were the power loss of the offshore WFs collector system, grid side converter (GSC) of WTs and high-voltage direct current (HVDC) converters. In [13], [14], MPC-based reactive power control methods were proposed for the large-scale WF that aim to keep all bus voltages inside the WF within a feasible range while reducing the network losses. In [15], [16], centralized optimal reactive power dispatch strategies were proposed for minimizing the total electrical losses of the WF, including not only losses in cables and WT transformers but also losses inside wind energy generation systems.

Centralized WF controllers gather information of all WTs inside the WF and generate reactive power references for them. A WF can be regarded as a constrained multiple input and multiple output system. The computation burden of the central controller dramatically increases with the size of WFs. A failure of the central controller significantly impacts the WF secure operation, implying low robustness. Moreover, the cost of communication is high. Several distributed algorithms can be used to address the problems above[17]. In [18], the ADMM was used to optimize the reactive power among the photovoltaic inverters in the distribution system. The distributed control has the advantages of robustness, cyber security, and the ability to perform parallel computation [19]. In [20], a two-tier voltage optimal control method was proposed for the large-scale wind farm cluster. The upper-tier control is realized by using the consensus protocol while the lower-tier control is achieved by using the ADMM algorithm. In [21], a distributed cooperative voltage control based on a consensus protocol was proposed for WFs. The aims are to regulate voltages within the feasible range while optimizing reactive power sharing among reactive power sources. In [22], a distributed model predictive control method was used in the WF optimal control. The aim is to reduce fatigue load of the WTs and keep the voltages of the buses within the feasible range. However, in the existing distributed optimal control of WFs, the dynamic control inside the WTs has not been considered in the WF control. Moreover, the distributed algorithm using the consensus protocol cannot obtain an optimal solution from the WF point of view. The optimal reactive power control using the ADMM algorithm still requires a central unit to coordinate each WT inside the WF.

Therefore, this paper proposes a distributed optimal reactive power control strategy (DORPC) for DFIG-based WFs that aims to minimize the total electrical loss inside a DFIG-based WF including the losses of generators, converters, filters, and network losses. First, the optimal control problem is transformed into an optimal power flow problem, which also considers DFIGs optimal operation. The loss model of the DFIG stator and rotor, converters, and filter are presented in detail. Second, a distributed optimization framework based on the consensus alternating direction method of multipliers (ADMM) is developed to solve the optimization problem in a distributed manner without loss of optimality. In the DORPC, each WT controller operates in parallel to generate the optimal reactive power references for the DFIG stator and the GSC, aiming to minimize the total losses inside the WF while tracking the reactive power dispatch command from the TSO.

The main contributions of this paper can be summarized as follows:

1. A DORPC scheme is designed to minimize losses in the DFIG-based WF. The proposed DORPC does not require a WF central controller while guaranteeing the optimality of the solution. The distributed controllers operate in parallel to generate the reactive power references for each DFIG stator and GSC while satisfying the grid requirements.

2. The distributed optimization framework based on ADMM is used to distribute the WF computation task to several distributed controllers. The DORPC strategy is computationally superior to the centralized strategy, both in convergence speed and optimization efficiency. Each controller communicates only with immediate neighbors, largely decreasing the cost of communication networks while guaranteeing optimality of control performance.

3. The exchanged information between controllers only includes the global, local, dual variables, instead of real measurement data from WTs, which implies cyber security and respects privacy of data. The DORPC strategy has the advantage of infor- 
mation privacy.

This paper is organized as follows. In Section II, the configuration of a WF and the framework of the DORPC scheme are presented. The loss model of each component in the WF is introduced in Section III. The consensus ADMM and the DORPC strategy are described in Section IV. The case study results are presented and discussed in Section V, followed by the conclusions.

\section{ADMM-based Distributed Optimal Reactive Power Control Scheme for DFIG-based WFs}

\subsection{Configuration of the WF}

Fig. 1 shows the typical configuration of a WF that connects to the external AC grid through an HV/MV transformer. The collector bus is connected to several feeders. Several DFIG-based WTs are connected to a feeder and placed 4-km apart.

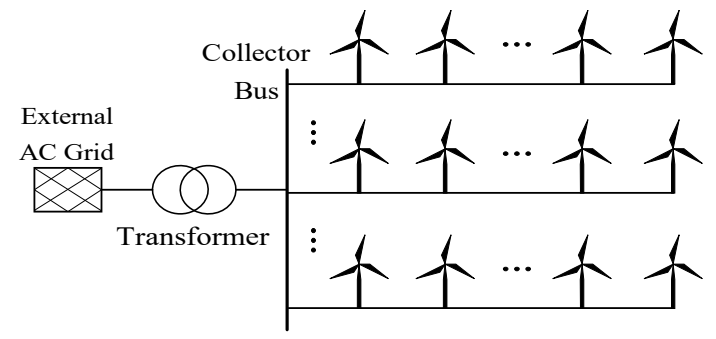

Fig. 1. The configuration of a wind farm.

\subsection{Concept of the ADMM-based DORPC}

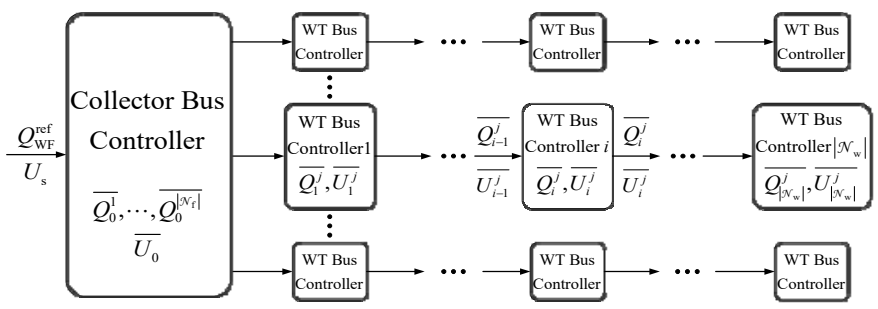

Fig. 2. The framework of the proposed DORPC.

Fig. 2 shows the structure of the proposed control scheme. The collector bus station and each DFIG-based WT are equipped with a controller. The reactive power reference $Q_{\mathrm{WF}}^{\text {ref }}$ is decided by the TSO and delivered to the collector bus station controller. In the DORPC, the WF operates in a distributed manner to minimize the total power losses inside the DFIG-based WF. Each controller operates only with the local measurements and data from the neighboring controllers. To minimize the total losses while tracking the WF reactive power dispatch command, the collector bus station controller and WT controllers cooperatively solve the optimization problem in a distributed fashion. Moreover, focusing on the main devices that cause losses in the WF, each WT controller generates optimal reactive power references for individual DFIG stator and GSC separately according to their loss models, thereby minimizing the generator copper, converter, and filter losses.

\section{Loss Model of Each Component in the WF}

The loss model of each component is presented in this section, including the loss models of the networks, DFIGs, converters, and filters.

\subsection{Loss Model of the Network}

The WF collector system is a radial distribution network, as shown in Fig. 3. The power flow from the external grid to the WT is defined as positive direction in this paper. In Fig. 3, node $\mathrm{s}$ is the slack bus, node 0 is the collector bus, $P_{\mathrm{s}}$ and $Q_{\mathrm{s}}$ are the active and reactive power from the slack bus to the collector bus, respectively, $P_{i}^{j}$ and $Q_{i}^{i}$ are the active and reactive power from bus $i$ 
to bus $i+1$ at the $j$ th feeder, $V_{\mathrm{s}}$ and $V_{0}$ represent the voltages of the slack bus and collector bus, respectively, $V_{i}^{j}$ is the voltage of bus $i$ at the $j$ th feeder, $P_{\mathrm{WT}, i}^{j}$ and $Q_{\mathrm{wT}, i}^{i}$ are the active and reactive power of the $i$ th DFIG-based WT at the $j$ th feeder, respectively, $\mathcal{N}_{\mathrm{F}}$ and $\mathcal{N}_{\mathrm{W}}$ denote the sets of WF feeders and WTs at each feeder, respectively.

Minimizing the networks losses is a global optimization problem. It is constrained by the voltage within feasible range constraints and DFIG-based WT rated power constraints. Since the voltage difference between bus $i$ and bus $i+1$ is much smaller than the voltages, and the losses of active and reactive power are much smaller than the power flows themselves. Thus, based on the linearized DistFlow (LinDistFlow) model [23], we can obtain the objective function for minimizing the WF networks losses as,

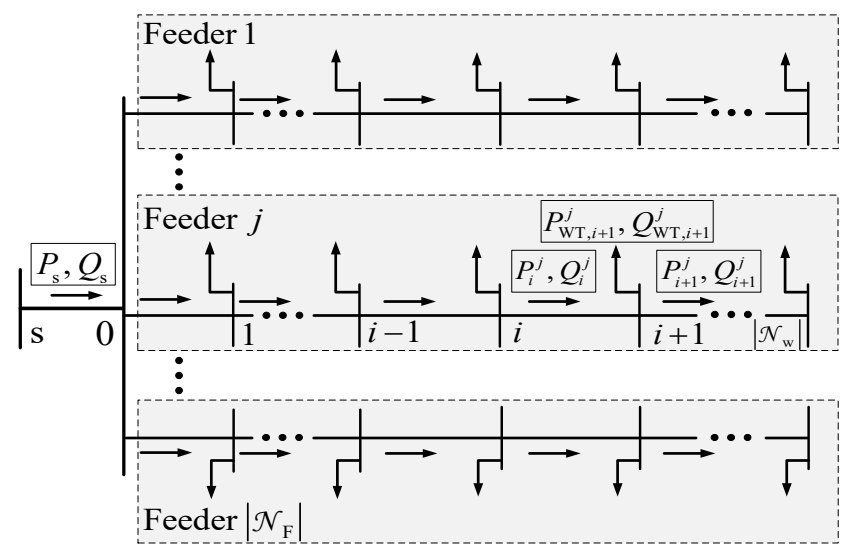

Fig. 3. Schematic diagram of the distribution network.

$$
\begin{gathered}
\min _{P, Q, V} R_{\mathrm{s}} \frac{\left(P_{\mathrm{s}}\right)^{2}+\left(Q_{\mathrm{s}}\right)^{2}}{V_{\mathrm{s}}^{2}}+\sum_{j=1}^{\left|\mathcal{N}_{\mathrm{f}}\right|} \sum_{i=0}^{\left|N_{\mathrm{w}}\right|} R_{i}^{j} \frac{\left(P_{i}^{j}\right)^{2}+\left(Q_{i}^{j}\right)^{2}}{V_{\mathrm{s}}^{2}} \\
\text { s.t. } \\
P_{i}^{j}=P_{i-1}^{j}-P_{\mathrm{WT}, i}^{j}, \\
Q_{i}^{j}=Q_{i-1}^{j}-Q_{\mathrm{WT}, i}^{j}, \\
U_{0}=U_{\mathrm{s}}-2\left(R_{\mathrm{s}} P_{\mathrm{s}}+X_{\mathrm{s}} Q_{\mathrm{s}}\right) \\
U_{1}^{j}=U_{0}-2\left(R_{0}^{j} P_{0}^{j}+X_{0}^{j} Q_{0}^{j}\right) \\
U_{i+1}^{j}=U_{i}^{j}-2\left(R_{i}^{j} P_{i}^{j}+X_{i}^{j} Q_{i}^{j}\right) \\
Q_{\mathrm{s}}=Q_{\mathrm{wF}}^{\mathrm{ref}}, P_{\left|\mathcal{N}_{\mathrm{w}}\right|}^{j}=0, Q_{\left|\mathcal{N}_{\mathrm{w}}\right|}^{j}=0, U_{\mathrm{s}}=0 \\
\left|Q_{i}^{j}-Q_{i-1}^{j}\right| \leq Q_{\mathrm{wT}, i}^{\mathrm{avi}, j}, \\
\left(\epsilon^{2}-2 \epsilon\right) V_{\mathrm{s}}^{2} \leq U_{i}^{j} \leq\left(\epsilon^{2}+2 \epsilon\right) V_{\mathrm{s}}^{2} .
\end{gathered}
$$

117 where $U_{0}$ is the difference between the square of collector bus voltage and the square of slack bus voltage, $U_{i}^{j}$ is the difference 118 between the square of the bus $i$ at the $j$ th feeder voltage and the square of slack bus voltage, $U_{i}^{j}=\left(V_{i}^{j}\right)^{2}-V_{\mathrm{s}}^{2}, R_{\mathrm{s}}$ and $X_{\mathrm{s}}$ are the resistance and reactance of the line segment between the slack bus and the collector bus, respectively, $R_{i}^{j}$ and $X_{i}^{j}$ are the resistance and reactance of the line segment between bus $i$ and bus $(i+1)$ at the $j$ th feeder, respectively, $\varepsilon$ is the constant for the voltage constraints, $Q_{\mathrm{WF}}^{\text {ref }}$ is the reactive power reference of the WF, and $Q_{\mathrm{WT}, i}^{\text {avi } i}$ is the available reactive power of the $i$ th $\mathrm{WT}$ at the $j$ th feeder. 


\subsection{Loss Model of DFIG}

Fig. 4 shows the basic configuration of a DFIG-based WT. The WT is connected to the DFIG through a gearbox. The DFIG stator directly connects to the WF AC collection system. The rotor is connected to the AC grid through a back-back PWM converter, which consists of a rotor-side converter (RSC) and a GSC. The converter rating is usually set to $25 \%-30 \%$ of the DFIG's nominal power [24]. The RSC is responsible for regulating the active and reactive power of the DFIG stator. The GSC is used for regulating the DC voltage at the DC link of the converter and providing a certain level of reactive power support for the WF. With the electronic converters, the active and reactive power of the DFIG-based WT can be controlled independently.

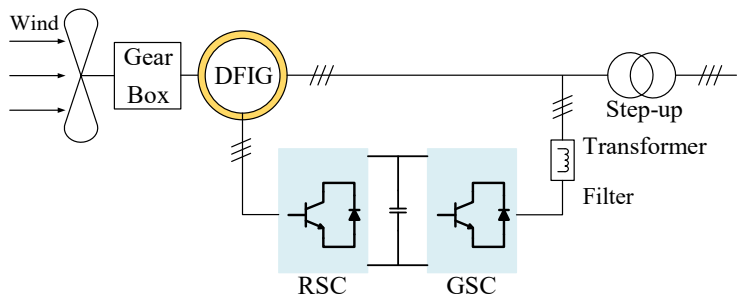

Fig. 4. DFIG-based wind power generation system.

The steady-state voltage equations for a DFIG which operates in a stator voltage-oriented reference frame can be expressed as follows [25]:

$$
\left[\begin{array}{c}
V_{\mathrm{s}} \\
0 \\
V_{\mathrm{dr}}^{\prime} \\
V_{\mathrm{qr}}^{\prime}
\end{array}\right]=\left[\begin{array}{cccc}
R_{\mathrm{s}} & -X_{\mathrm{s}} & 0 & -X_{\mathrm{m}} \\
X_{\mathrm{s}} & R_{\mathrm{s}} & X_{\mathrm{m}} & 0 \\
0 & -s X_{\mathrm{m}} & R_{\mathrm{r}}^{\prime} & -s X_{\mathrm{r}}^{\prime} \\
s X_{\mathrm{m}} & 0 & s X_{\mathrm{r}}^{\prime} & R_{\mathrm{r}}^{\prime}
\end{array}\right]\left[\begin{array}{c}
I_{\mathrm{ds}} \\
I_{\mathrm{qs}} \\
I_{\mathrm{dr}}^{\prime} \\
I_{\mathrm{qr}}^{\prime}
\end{array}\right],
$$

where $V_{\mathrm{s}}$ is the stator voltage, $V_{\mathrm{dr}}$ and $V_{\mathrm{qr}}$ are the rotor steady-state d-axis and q-axis voltage, respectively. $I_{\mathrm{ds}}, I_{\mathrm{qs}}, I_{\mathrm{dr}}$, and $I_{\mathrm{qr}}$ are the steady-state d-axis and q-axis currents of the rotor and the stator, respectively, the superscript ' is used for rotor value referred to the stator, $R_{\mathrm{S}}$ and $R_{\mathrm{r}}$ are the equivalent resistances of the stator and rotor, respectively, $X_{\mathrm{S}}$ is the reactance of the stator, $X_{\mathrm{r}}$ is the reactance of the rotor, $X_{\mathrm{m}}$ is the mutual reactance, and $s$ is the slip ratio.

The following two equations can be obtained from the steady-state voltage equations:

$$
\begin{gathered}
V_{\mathrm{s}}=R_{\mathrm{s}} I_{\mathrm{ds}}-X_{\mathrm{s}} I_{\mathrm{qs}}-X_{\mathrm{m}} I_{\mathrm{qr}}^{\prime}, \\
0=X_{\mathrm{s}} I_{\mathrm{ds}}+R_{\mathrm{s}} I_{\mathrm{qs}}+X_{\mathrm{m}} I_{\mathrm{dr}}^{\prime} .
\end{gathered}
$$

$I_{\mathrm{qs}}$ and $I_{\mathrm{dr}}$ can be presented as,

$$
\begin{gathered}
I_{\mathrm{qs}}=Q_{\mathrm{s}} / V_{\mathrm{s}}, \\
I_{\mathrm{dr}}^{\prime}=-\frac{X_{\mathrm{s}}}{V_{\mathrm{s}} X_{\mathrm{m}}} \frac{\omega_{\mathrm{s}}}{\omega_{\mathrm{r}}} P_{\mathrm{mec}}, \quad I_{\mathrm{dr}}=u I_{\mathrm{dr}}^{\prime} .
\end{gathered}
$$

Substituting (11) and (12) into (9) and (10),

$$
\begin{gathered}
V_{\mathrm{s}}=R_{\mathrm{s}} I_{\mathrm{ds}}-X_{\mathrm{s}} \frac{Q_{\mathrm{s}}}{V_{\mathrm{s}}}-X_{\mathrm{m}} I_{\mathrm{qr}}^{\prime}, \\
0=X_{\mathrm{s}} I_{\mathrm{ds}}+R_{\mathrm{s}} \frac{Q_{\mathrm{s}}}{V_{\mathrm{s}}}-\frac{X_{\mathrm{s}}}{V_{\mathrm{s}}} \frac{\omega_{\mathrm{s}}}{\omega_{\mathrm{r}}} P_{\mathrm{mec}}
\end{gathered}
$$


Then $I_{\mathrm{ds}}$ and $I_{\mathrm{qr}}$ can be derived from (13) and (14), and expressed as,

$$
\begin{gathered}
I_{\mathrm{ds}}=-\frac{R_{\mathrm{s}}}{X_{\mathrm{s}}} \frac{1}{V_{\mathrm{s}}} Q_{\mathrm{s}}+\frac{1}{V_{\mathrm{s}}} \frac{\omega_{\mathrm{s}}}{\omega_{\mathrm{r}}} P_{\mathrm{mec}}, \\
I_{\mathrm{qr}}^{\prime}=-\frac{\left(R_{\mathrm{s}}^{2}+X_{\mathrm{s}}^{2}\right)}{X_{\mathrm{s}}} \frac{1}{X_{\mathrm{m}} V_{\mathrm{s}}} Q_{\mathrm{s}}+\frac{R_{\mathrm{s}}}{X_{\mathrm{m}} V_{\mathrm{s}}} \frac{\omega_{\mathrm{s}}}{\omega_{\mathrm{r}}} P_{\mathrm{mec}}-\frac{V_{\mathrm{s}}}{X_{\mathrm{m}}}, \quad I_{\mathrm{qr}}=u I_{\mathrm{qr}}^{\prime} .
\end{gathered}
$$

$I_{\mathrm{ds}}, I_{\mathrm{qs}}, I_{\mathrm{dr}}$, and $I_{\mathrm{qr}}$ can be expressed as,

$$
\begin{gathered}
I_{\mathrm{ds}}=-\frac{M}{V_{\mathrm{s}}} Q_{\mathrm{s}}+\frac{1}{V_{\mathrm{s}}} P_{\mathrm{sr}}, \quad I_{\mathrm{qs}}=\frac{1}{V_{\mathrm{s}}} Q_{\mathrm{s}}, \\
I_{\mathrm{dr}}=-\frac{u X_{\mathrm{s}}}{V_{\mathrm{s}} X_{\mathrm{m}}} P_{\mathrm{sr}}, \quad I_{\mathrm{qr}}=-\frac{u}{N X_{\mathrm{m}} V_{\mathrm{s}}} Q_{\mathrm{s}}+\frac{u R_{\mathrm{s}}}{X_{\mathrm{m}} V_{\mathrm{s}}} P_{\mathrm{sr}}-\frac{u V_{\mathrm{s}}}{X_{\mathrm{m}}} .
\end{gathered}
$$

142 where $M=\frac{R_{\mathrm{s}}}{X_{\mathrm{s}}}, N=\frac{X_{\mathrm{s}}}{\left(R_{\mathrm{s}}^{2}+X_{\mathrm{s}}^{2}\right)}$, and $P_{\mathrm{sr}}=\frac{\omega_{\mathrm{s}}}{\omega_{\mathrm{r}}} P_{\mathrm{mec}}$. Rewriting (17) and (18) into the matrix form with variable $Q_{\mathrm{s}}$,

$$
\left[\begin{array}{llll}
I_{\mathrm{ds}} & I_{\mathrm{qs}} & I_{\mathrm{dr}} & I_{\mathrm{qr}}
\end{array}\right]^{\mathrm{T}}=A Q_{\mathrm{s}}+B
$$

143 where $A=\left[\begin{array}{llll}\frac{M}{V_{\mathrm{s}}} & \frac{1}{V_{\mathrm{s}}} & 0 & -\frac{u}{N X_{\mathrm{m}} V_{\mathrm{s}}}\end{array}\right]^{\mathrm{T}}, B=\left[\begin{array}{llll}\frac{P_{\mathrm{sr}}}{V_{\mathrm{s}}} & 0 & -\frac{u X_{\mathrm{s}} P_{\mathrm{sr}}}{V_{\mathrm{s}} X_{\mathrm{m}}} & \frac{u R_{\mathrm{s}} P_{\mathrm{sr}}}{X_{\mathrm{m}} V_{\mathrm{s}}}\end{array}-\frac{u V_{\mathrm{s}}}{X_{\mathrm{m}}}\right]^{\mathrm{T}}$.

144 Then, the copper losses of the DFIG can be obtained,

$$
P_{\mathrm{DFIG}}^{\mathrm{Loss}}=R_{\mathrm{s}}\left(I_{\mathrm{ds}}^{2}+I_{\mathrm{qS}}^{2}\right)+R_{\mathrm{r}}\left(I_{\mathrm{dr}}^{2}+I_{\mathrm{qr}}^{2}\right) .
$$

145

146

147

148

149

\subsection{Loss Model of Converters and Filter}

The losses of the converter can be divided into switching and conducting losses, which dissipate in the form of thermal energy, reduces the service life of the converters and causes adverse effects on the system. According to [16], the loss model of converters can be represented by the following piecewise linearized curve equation,

$$
P_{\text {con }}^{\text {Loss }}=P_{\mathrm{c}}+R_{\mathrm{c}}\left(I_{\mathrm{rms}}^{2}-c_{0}^{2}\right) .
$$

The parameters in (21) can be presented as,

$$
\begin{aligned}
& \left\{\begin{array}{lc}
P_{\mathrm{c}}=0, R_{\mathrm{c}}=7.90 \times 10^{-4}, c_{0}=0 & I_{\mathrm{rms}} \leq 0.17 \\
P_{\mathrm{c}}=2.73 \times 10^{-5}, R_{\mathrm{c}}=2.91 \times 10^{-4}, c_{0}=0.17 & 0.17<I_{\text {rms }} \leq 0.52 \\
P_{\mathrm{c}}=1.15 \times 10^{-4}, R_{\mathrm{c}}=2.20 \times 10^{-4}, c_{0}=0.52 & 0.52<I_{\mathrm{rms}} \leq 1
\end{array},\right. \\
& I_{\mathrm{RSC}}^{\mathrm{rms}}=\sqrt{I_{\mathrm{dr}}^{2}+I_{\mathrm{qr}}^{2}}, \\
& I_{\mathrm{GSC}}^{\mathrm{rms}}=\sqrt{I_{\mathrm{dg}}^{2}+I_{\mathrm{qg}}^{2}} .
\end{aligned}
$$

$I_{\mathrm{RSC}}^{\mathrm{ms}}$ and $I_{\mathrm{GSC}}^{\mathrm{rms}}$ are the rms values of the current flows through the RSC and GSC, respectively. $I_{\mathrm{dg}}$ and $I_{\mathrm{qg}}$ are the d-axis and q-axis currents of the GSC, which can be calculated respectively as, 


$$
\begin{gathered}
I_{\mathrm{dg}}=\left(I_{\mathrm{dr}} V_{\mathrm{dr}}+I_{\mathrm{qr}} V_{\mathrm{qr}}\right) / V_{\mathrm{s}}, \\
I_{\mathrm{qg}}=Q_{\mathrm{g}} / V_{\mathrm{s}}, \\
Q_{\mathrm{wT}}=Q_{\mathrm{g}}+Q_{\mathrm{s}},
\end{gathered}
$$

152 where $Q_{\mathrm{g}}$ is the reactive power provided by the GSC, and $Q_{\mathrm{WT}}$ is the reactive power output of the DFIG-based WT.

153 Calculating the d-axis current of the GSC using (25) will produce the quartic items of $Q_{\text {s }}$, which complicates the calculation 154 extremely. Further transformation calculation should be conducted for $I_{\mathrm{dg}}$. The active power on the stator side and rotor side are 155 presented as follows,

$$
P_{\mathrm{r}}=I_{\mathrm{dr}} V_{\mathrm{dr}}+I_{\mathrm{qr}} V_{\mathrm{qr}}, \quad P_{\mathrm{s}}=I_{\mathrm{ds}} V_{\mathrm{s}}, \quad P_{\mathrm{r}}=-s P_{\mathrm{s}} .
$$

156 Then, substituting (28) into (25), $I_{\mathrm{dg}}$ can be restated as,

$$
I_{\mathrm{dg}}=-s I_{\mathrm{ds}} .
$$

Then, the RSC and GSC losses $P_{\mathrm{RSC}}^{\mathrm{Loss}}$, and $P_{\mathrm{GSC}}^{\mathrm{Loss}}$ are given by,

$$
\begin{aligned}
& P_{\mathrm{RSC}}^{\mathrm{Loss}}=P_{\mathrm{cr}}+R_{\mathrm{cr}}\left(I_{\mathrm{RSC}}^{\mathrm{rms} 2}-c_{\mathrm{r}}^{2}\right), \\
& P_{\mathrm{GSC}}^{\mathrm{Loss}}=P_{\mathrm{cg}}+R_{\mathrm{cg}}\left(I_{\mathrm{GSC}}^{\mathrm{rms} 2}-c_{\mathrm{g}}^{2}\right),
\end{aligned}
$$

The loss in the grid-side filter $P_{\text {fil }}^{\mathrm{Loss}}$ can be expressed as,

$$
P_{\text {fil }}^{\text {Loss }}=R_{\mathrm{fil}}\left(I_{\mathrm{dg}}^{2}+I_{\mathrm{qg}}^{2}\right),
$$

where $R_{\mathrm{fil}}$ is the equivalent resistance of filter.

The total losses of a DFIG-based WT can be calculated as

$$
P_{\mathrm{WT}}^{\mathrm{Loss}}=P_{\mathrm{DFIG}}^{\mathrm{Loss}}+P_{\mathrm{RSC}}^{\mathrm{Loss}}+P_{\mathrm{GSC}}^{\mathrm{Loss}}+P_{\mathrm{fil}}^{\mathrm{Loss}} .
$$

\subsection{Optimization Problem}

In the DFIG-based WF operation, all DFIG-based WTs inside the WF are assumed to be operated in maximum power point track (MPPT) mode. The active power output of the DFIG at each control period can be considered constant. The WF operator only generates the optimal reactive power references for the DFIG stator and GSC to minimize the total power losses inside the

$$
\begin{gathered}
\min _{Q_{s}, Q_{\mathrm{g}}} R_{\mathrm{s}} \frac{\left(Q_{\mathrm{s}}\right)^{2}}{V_{\mathrm{s}}^{2}}+\sum_{j=1}^{\left|\mathcal{N}_{\mathrm{f}}\right|} \sum_{i=1}^{|| \mathcal{N}_{\mathrm{w}} \mid}\left(R_{i-1}^{j} \frac{\left(Q_{i-1}^{j}\right)^{2}}{V_{\mathrm{s}}^{2}}+P_{\mathrm{WT}, i}^{\mathrm{Loss}, j}\right), \\
\text { s.t. }(4)(5)(7) \\
Q_{i}^{j}-Q_{i-1}^{j}=Q_{\mathrm{s}, i}^{j}+Q_{\mathrm{g}, i}^{j}, \\
-Q_{\mathrm{s}, i}^{\mathrm{avi}, j} \leq Q_{\mathrm{s}, i}^{j} \leq Q_{\mathrm{s}, i}^{\mathrm{avi}, j},
\end{gathered}
$$




$$
-Q_{\mathrm{g}, i}^{\mathrm{avi}, j} \leq Q_{\mathrm{g}, i}^{j} \leq Q_{\mathrm{g}, i}^{\mathrm{avi}, j}
$$

where $Q_{\mathrm{s}, i}^{j}$ and $Q_{\mathrm{g}, i}^{j}$ are the reactive power provided by the stator and the GSC of the $i$ th DFIG-based WT at the $j$ th feeder, respectively, $Q_{\mathrm{s}, i}^{\mathrm{avi}, j}$ and $Q_{\mathrm{g}, i}^{\mathrm{avi}, j}$ are the available reactive power of the stator and the GSC, respectively. The first item of (34) is the network loss between the collector bus and slack bus. The second item of (34) is the network loss in each feeder and the generator loss, converter loss, and filter loss of the DFIG. The problem of (34)-(37) is a centralized optimization problem. The decision variables are the reactive power references for the DFIG stator and GSC. Eq. (35) is used to ensure the reactive power generated from DFIG stator and GSC is within reactive power flow constraints. Eqs. (36) and (37) are the boundary constraints of the reactive power of the stator and GSC, respectively.

\section{Distributed Optimal Reactive Power Control Scheme}

\subsection{Consensus ADMM-Based Formulation}

The ADMM is a computational framework for solving the optimization problem and is suitable for solving the convex optimization problem in a distributed fashion. By the decomposition and coordination process, the ADMM decomposes the large global problem into several small and easily solved local sub-problems and obtains the solution of the large global problem by coordinating the solutions of the sub-problems. The problem (34) is an optimization problem that can be efficiently solved in parallel by the consensus ADMM.

The collector bus station controller and each WT controller iteratively solve the local optimization problem with local constraints and share global variables with their neighbors. Each controller generates the optimal local variables and is subjected to the condition that all local variables are equal to the corresponding global variables. After several iterations, all local variables converge to the global optimal value and thus achieve optimal performance. For the $i$ th controller at the $j$ th feeder, it keeps local variables $Q_{i}^{j}$ and $U_{i}^{j}$, which are defined as $\overline{Q_{i}^{j}}$ and $\overline{U_{i}^{j}}$, and the controller also keeps local variables $Q_{i-1}^{j}$ and $U_{i-1}^{j}$ from the (i-1)th controller, which are defined as $\underline{Q_{i}^{j}}$ and $\underline{U_{i}^{j}}$, respectively.

Assume that active power are auxiliary constant parameters, which can be measured by each controller, then (34) can be formulated as a consensus ADMM problem as follows:

$$
\begin{gathered}
\min _{Q_{s}, Q_{\mathrm{g}}} R_{\mathrm{s}} \frac{\left(Q_{0}\right)^{2}}{V_{\mathrm{s}}^{2}}+\sum_{j=1}^{\left|\mathcal{N}_{\mathrm{f}}\right||| \mathcal{N}_{\mathrm{w}} \mid}\left(R_{i=1}^{j} \frac{\left(Q_{i}^{j}\right)^{2}}{V_{\mathrm{s}}^{2}}+P_{\mathrm{WT}, i}^{\mathrm{Loss}, j}\right), \\
\overline{U_{0}}=\underline{U_{0}}-2\left(R_{\mathrm{s}} P_{\mathrm{s}}+X_{\mathrm{s}} \underline{Q_{0}}\right) \\
\overline{U_{i}^{j}}=\underline{U_{i}^{j}}-2\left(R_{i-1}^{j} P_{i-1}^{j}+X_{i-1}^{j} \underline{Q_{i}^{j}}\right) \\
\left(\epsilon^{2}-2 \epsilon\right) V_{\mathrm{s}}^{2} \leq \overline{U_{i}^{j}} \leq\left(\epsilon^{2}+2 \epsilon\right) V_{\mathrm{s}}^{2}, \\
\underline{Q_{0}}=Q_{\mathrm{WF}}^{\mathrm{ref}}, \overline{Q_{i}^{j}}=Q_{i}^{j}, \underline{Q_{i}^{j}}=Q_{i-1}^{j}, \overline{Q_{\left|\mathfrak{N}_{\mathrm{w}}\right|}^{j}}=0 \\
\underline{U_{0}}=0, \underline{U_{1}^{j}}=U_{0}, \overline{U_{i}^{j}}=U_{i}^{j}, \underline{U_{i}^{j}}=U_{i-1}^{j},
\end{gathered}
$$




$$
\begin{aligned}
& \overline{Q_{i}^{j}}-\underline{Q_{i}^{j}}=Q_{\mathrm{s}, i}^{j}+Q_{\mathrm{g}, i}^{j}, \\
& -Q_{\mathrm{s}, i}^{\mathrm{avi}, j} \leq Q_{\mathrm{s}, i}^{j} \leq Q_{\mathrm{s}, i}^{\mathrm{avi}, j}, \\
& -Q_{\mathrm{g}, i}^{\mathrm{avi}, j} \leq Q_{\mathrm{g}, i}^{j} \leq Q_{\mathrm{g}, i}^{\mathrm{avi}, j} .
\end{aligned}
$$

$$
\begin{aligned}
f_{0}= & R_{\mathrm{s}} \frac{\left(Q_{0}\right)^{2}}{V_{\mathrm{s}}^{2}}+y_{0}^{j \underline{\underline{Q}}}\left(\underline{Q_{0}}-Q_{\mathrm{s}}\right)+\sum_{j=1}^{\left|\mathcal{N}_{\mathrm{f}}\right|} y_{0}^{j \bar{Q}}\left(\overline{Q_{0}^{j}}-Q_{0}^{j}\right)+y_{0}^{j \underline{U}}\left(\underline{U_{0}}-U_{\mathrm{s}}\right)+y_{0}^{j \bar{U}}\left(\overline{U_{0}}-U_{0}\right) \\
& +\frac{\sigma}{2}\left(\underline{Q_{0}}-Q_{\mathrm{s}}\right)^{2}+\sum_{j=1}^{\left|\mathcal{N}_{\mathrm{f}}\right|} \frac{\sigma}{2}\left(\overline{Q_{0}^{j}}-Q_{0}^{j}\right)^{2}+\frac{\sigma}{2}\left(\underline{U_{0}}-U_{\mathrm{s}}\right)^{2}+\frac{\sigma}{2}\left(\overline{U_{0}}-U_{0}\right)^{2}
\end{aligned}
$$

where $y_{0}^{j \underline{\underline{Q}}}, y_{0}^{j \bar{Q}}, y_{0}^{j \underline{\underline{U}}}$, and $y_{0}^{j \bar{U}}$ are the dual variables. $\sigma>0$ is the penalty for the local variables being different from the global variables, which is obtained by experience.

For the $i$ th WT controller at the $j$ th feeder, the solution for the optimization is same to the collector bus station controller, which can be expressed as

$$
\min f_{i}^{j}\left(\underline{Q_{i}^{j}}, \overline{Q_{i}^{j}}, \underline{U_{i}^{j}}, \overline{U_{i}^{j}}, Q_{s, i}^{j}, Q_{\mathrm{g}, i}^{j}\right),
$$

$$
\text { s.t. }(39)-(45) \text {. }
$$

where

$$
\begin{aligned}
f_{i}^{j}= & R_{i-1}^{j} \frac{\left(Q_{i}^{j}\right)^{2}}{V_{\mathrm{s}}^{2}}+P_{\mathrm{WT}, i}^{\mathrm{Loss}, j} \\
& +y_{i}^{j \underline{\underline{Q}}}\left(\underline{Q_{i}^{j}}-Q_{i-1}^{j}\right)+y_{i}^{j \bar{Q}}\left(\overline{Q_{i}^{j}}-Q_{i}^{j}\right)+y_{i}^{j \underline{U}}\left(\underline{U_{i}^{j}}-U_{i-1}^{j}\right)+y_{i}^{j \bar{U}}\left(\overline{U_{i}^{j}}-U_{i}^{j}\right), \\
& +\frac{\sigma}{2}\left(\underline{Q_{i}^{j}}-Q_{i-1}^{j}\right)^{2}+\frac{\sigma}{2}\left(\overline{Q_{i}^{j}}-Q_{i}^{j}\right)^{2}+\frac{\sigma}{2}\left(\underline{U_{i}^{j}}-U_{i-1}^{j}\right)^{2}+\frac{\sigma}{2}\left(\overline{U_{i}^{j}}-U_{i}^{j}\right)^{2}
\end{aligned}
$$

The proposed DORPC scheme iteratively minimizes the augmented Lagrangian by performing following updates. Here, we only present the iteration for the WT bus controller. The collector bus station controller follows the similar process.

\subsubsection{Initialize}


Assign 0 to all local, global and dual variables at the first iteration:

$$
x_{i}^{[1]}=0, \quad y_{i}^{[1]}=0, \quad z_{i}^{[1]}=0 .
$$

204 where $x, y$, and $z$ are the following column matrixes:

$$
\begin{aligned}
& x_{i}=\left[\begin{array}{llllll}
\frac{Q_{i}^{j}}{Q_{i}^{j}} & \underline{U_{i}^{j}} & \overline{U_{i}^{j}} & Q_{\mathrm{s}, i}^{j} & Q_{\mathrm{g}, i}^{j}
\end{array}\right]^{\mathrm{T}}, \\
& y_{i}=\left[\begin{array}{llll}
y_{i}^{j \underline{Q}} & y_{i}^{j \bar{Q}} & y_{i}^{j \underline{U}} & y_{i}^{j \bar{U}}
\end{array}\right]^{\mathrm{T}}, \\
& z_{i}=\left[\begin{array}{llll}
Q_{i-1}^{j} & Q_{i}^{j} & U_{i-1}^{j} & U_{i}^{j}
\end{array}\right]^{\mathrm{T}} .
\end{aligned}
$$

\subsubsection{Update local variables}

To get the optimal value, each bus controller should fix the value of the global variables and the dual variables at the $k$ th step.

$$
x_{i}^{[k+1]}=\arg \min _{x} f_{i}^{j}\left(x_{i}, y_{i}^{[k]}, z_{i}^{[k]}\right),
$$

s.t. $(39)-(45)$.

211 Solve the problem above with the constraints to update local variables.

\section{4.2.3. Update global variables}

213 After updating the local variables, each controller gathers information from their neighbor controllers and updates the global 214 variables by,

$$
\begin{aligned}
Q_{\left|\mathcal{N}_{\mathrm{w}}\right|}^{j}{ }^{[k+1]} & =0, U_{\left|\mathcal{N}_{\mathrm{w}}\right|}^{j}{ }^{[k+1]}={\overline{U_{\left|\mathcal{N}_{\mathrm{w}}\right|}^{j}}}^{[k+1]}, \\
Q_{i}^{j[k+1]} & =\frac{1}{2}\left({\overline{Q_{i}^{j}}}^{[k+1]}+{\underline{Q_{i+1}^{j}}}^{[k+1]}\right), \\
U_{i}^{j[k+1]} & =\frac{1}{2}\left({\overline{U_{i}^{j}}}^{[k+1]}+{\underline{U_{i+1}^{j}}}^{[k+1]}\right) .
\end{aligned}
$$

\subsubsection{Update dual variables:}

The dual variables of the $i$ th controller at the $j$ th feeder that disagree with the global variables in the previous iteration, which are stored in local controller, are updated according to the following rules for each node:

$$
y_{i}^{[k+1]}=y_{i}^{[k]}+\sigma\left(x_{i}^{[k+1]}-z_{i}^{[k+1]}\right) .
$$

218 where $x_{i}^{\prime}=\left[\begin{array}{llll}\underline{Q_{i}^{j}} & \overline{Q_{i}^{j}} & \underline{U_{i}^{j}} & \overline{U_{i}^{j}}\end{array}\right]^{\mathrm{T}}$.

\subsubsection{Check stopping conditions}

$$
\begin{gathered}
x_{i}^{[k+1]}-x_{i}^{[k]} \leq v_{1}, x_{i}^{[k+1]}-z_{i}^{[k+1]} \leq v_{1}, \\
\frac{f_{i}\left(x_{i}^{[k+1]}\right)-f_{i}\left(x_{i}^{[k]}\right)}{f_{i}\left(x_{i}^{[k]}\right)} \leq v_{2},
\end{gathered}
$$


After a moderate number of iterations, the local and global variables will converge to the same values. Once the algorithm converges, the local variables will correspond to an optimized feasible solution for the WF operation without loss of optimality of the primal problem.

Fig. 5 shows the flowchart of the proposed DORPC scheme. The $i$ th WT bus at the $j$ th feeder of the WF is used as an example to illustrate the procedure of the DORPC. The calculation task is divided to several controllers inside the WF, which includes setting the initial value, solving the small-scale optimization problem, updating global variables and dual variables, and checking the stop condition. The computation burden could be reduced efficiently and the requirement of the central unit is eliminated.

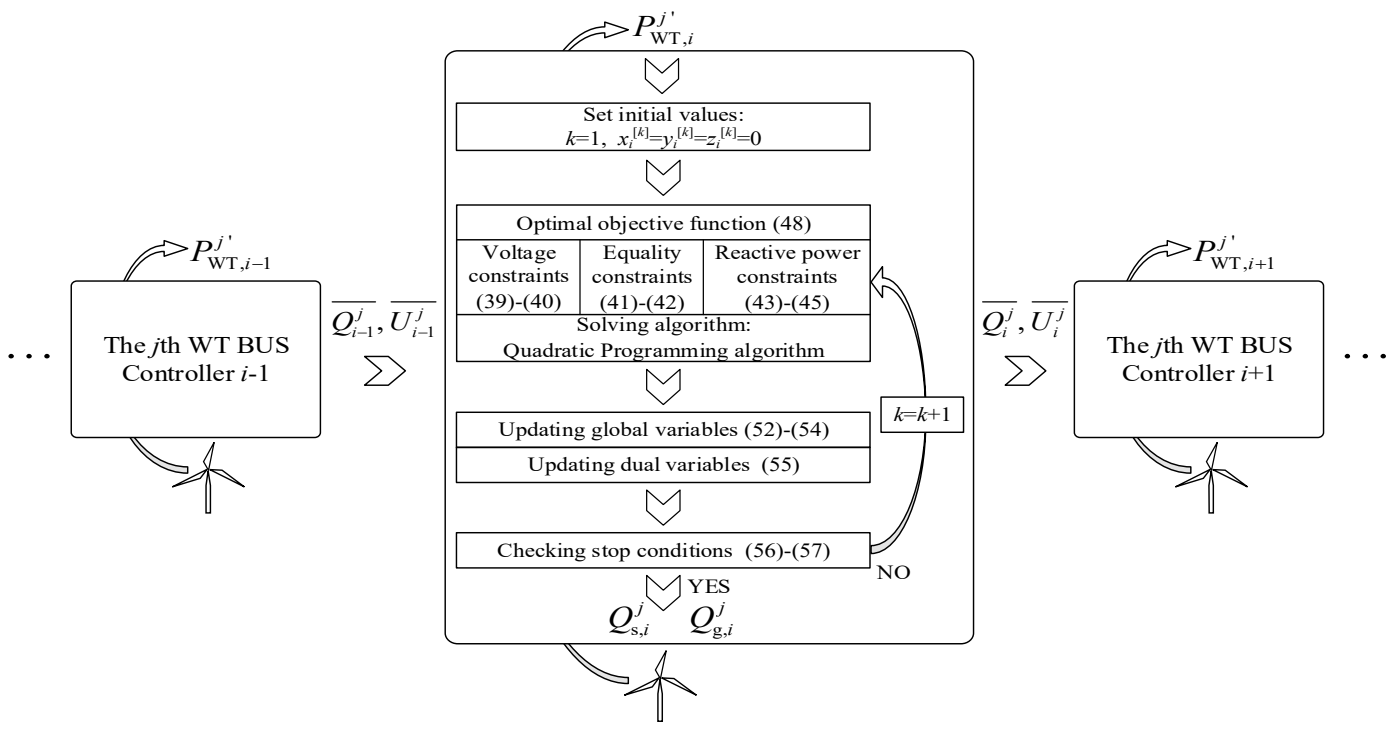

Fig. 5. The flowchart of the proposed DORPC.

\section{Simulation Results}

\subsection{Case Study}

A WF with two feeders and $10 \times 5$ MW DFIG-based WTs connected to each feeder is used for validating the performance of the proposed DORPC method. The parameters of the DFIG-based WF are listed in Table I.

\section{TABLE I}

PARAMETERS OF THE DFIG-BASED WF

\begin{tabular}{|c|c|c|c|c|c|}
\hline Parameters & Value & Per Unit Value & Parameters & Value & Per Unit Value \\
\hline Rated Mechanical Power of the WT & $5 \mathrm{MW}$ & 0.05 p.u. & Filter Resistance, $R_{\mathrm{fil}}$ & $0.6791 \mathrm{~m} \Omega$ & 0.000062 p.u. \\
\hline Rated Stator Phase Voltage & $548.48 \mathrm{~V}(\mathrm{rms})$ & 0.017 p.u. & Resistance of $0.9 / 33 \mathrm{kV}$ Transformer, $R_{\mathrm{T}}$ & $0.08712 \Omega$ & 0.008 p.u. \\
\hline Rated Stator Frequency & $50 \mathrm{~Hz}$ & & Reactance of $0.9 / 33 \mathrm{kV}$ Transformer, $X_{\mathrm{T}}$ & $0.6534 \Omega$ & 0.06 p.u. \\
\hline Rated Rotor Speed & $1170 \mathrm{rpm}$ & & Rated capacity of $0.9 / 33 \mathrm{kV}$ Transformer & $5 \mathrm{MVA}$ & 0.05 p.u. \\
\hline Rated Slip & -0.17 & & Distance between Adjacent DFIGs & $4 \mathrm{~km}$ & \\
\hline Number of Pole Pairs & 3 & & Line Resistance, $R_{i}^{j}$ & $0.134 \Omega / \mathrm{km}$ & 0.012305 p.u. \\
\hline Stator Winding Resistance, $R_{\mathrm{s}}$ & $1.552 \mathrm{~m} \Omega$ & 0.000142 p.u. & Line Reactance, $X_{i}^{j}$ & $0.129 \Omega / \mathrm{km}$ & 0.011872 p.u. \\
\hline Rotor Winding Resistance, $R_{\mathrm{r}}$ & $1.446 \mathrm{~m} \Omega$ & 0.000133 p.u. & Rated WF Power, $S_{\mathrm{WF}}$ & 100 MVA & 1.0 p.u. \\
\hline Stator Leakage Reactance, $X_{\mathrm{ls}}$ & $0.400 \Omega$ & 0.0367 p.u. & Base Current, $I_{\mathrm{B}}$ & $1749.5 \mathrm{~A}(\mathrm{rms})$ & 1.0 p.u. \\
\hline Rotor Leakage Reactance, $X_{\mathrm{lr}}$ & $0.375 \Omega$ & 0.0323 p.u. & Base Impedance, $Z_{\mathrm{B}}$ & $10.89 \Omega$ & 1.0 p.u. \\
\hline Magnetizing Reactance, $X_{\mathrm{m}}$ & $1.733 \Omega$ & 0.1591 p.u. & & & \\
\hline
\end{tabular}




\subsection{Control strategies}

Strategy A: DORPC Strategy

Strategy A is the proposed DORPC scheme, which minimizes the losses of network and the DFIG WT. The objective functions are (46) and (48).

Strategy B: Traditional Proportional Dispatch Strategy

Strategy B is the traditional PD strategy. The reactive power is provided by the stator. The reactive power references of the WT are calculated as,

$$
Q_{\mathrm{WT}, i}^{\mathrm{ref}, j}=\frac{Q_{\mathrm{WT}, i}^{\mathrm{avi}, j}}{\sum_{j=1}^{\left|\mathfrak{N}_{\mathrm{f}}\right|} \sum_{i=1}^{\mathfrak{N}_{\mathrm{w}} \mid} Q_{\mathrm{WT}, i}^{\mathrm{avi}, j}} Q_{\mathrm{WF}}^{\mathrm{ref}} .
$$

Strategy C: DORPC Strategy without the Optimization of DFIG WT Losses

Strategy $\mathrm{C}$ is the DORPC strategy without the optimization of DFIG WT losses, which minimizes the network losses only.

\subsection{Control performance of DORPC}

Performance is discussed in this subsection. To verify the effectiveness of the proposed DORPC, the reference value of the reactive power for the WF is set as 0.1 p.u. and 0.2 p.u. . The total simulation time is set as $600 \mathrm{~s}$.

The available wind power of the WF is shown in Fig. 6. From $0 \mathrm{~s}$ to $250 \mathrm{~s}$, the total available wind power fluctuates between 65 and $75 \mathrm{MW}$. The total available power gradually rises from $250 \mathrm{~s}$ to $400 \mathrm{~s}$, and the maximal total available wind power is $90 \mathrm{MW}$. After $400 \mathrm{~s}$, the total available wind power decreases gradually.

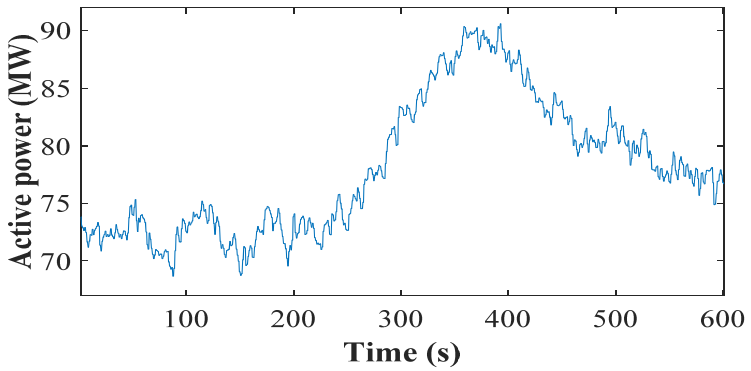

Fig. 6. Total available wind power for WF.

The convergence performance of the DORPC scheme when the reactive power reference of the WF is set to 0.2 p.u. is shown in Fig. 7. Given the excessive amount of data, only the convergence performance of the local variables of the collector bus station and the first five WT buses are shown here. Simulation results reveal that the local variables converge to a common value after 40 iterations, implying good convergence performance. It takes about 4-7 ms to complete an iteration. As a result, the time required to complete an optimization is less than $0.3 \mathrm{~s}$.

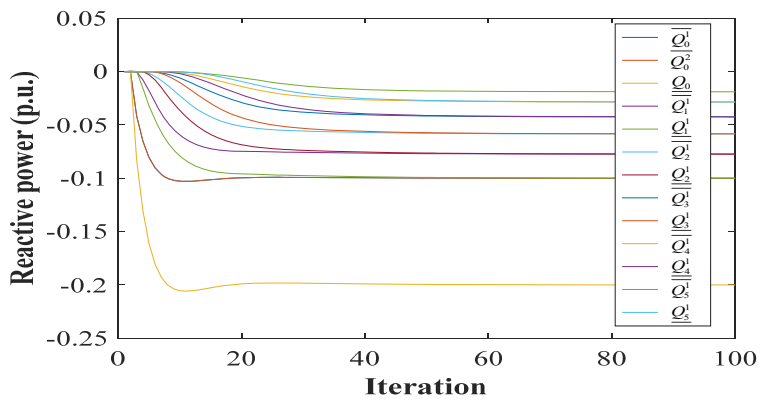

Fig. 7. Convergence performance with reactive power reference of WF set to 0.2 p.u.

Fig. 8 shows the reactive power output of the 1st WT at the 1st feeder when the reactive power reference of the WF is set as 
0.2 p.u. . $Q_{\mathrm{s}}$ and $Q_{\mathrm{g}}$ begin to fluctuate simultaneously at $300 \mathrm{~s}$ to $400 \mathrm{~s}$ given the decrease in the available reactive power with the increasing active power output.

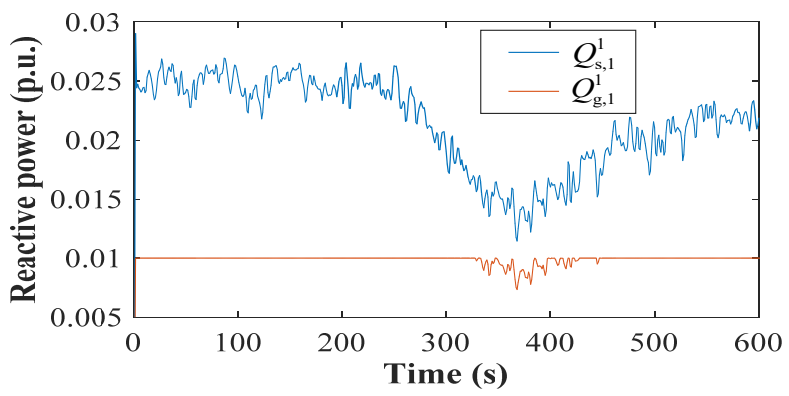

Fig. 8. Reactive power dispatch inside 1st DFIG-based WT at 1st feeder with WF reactive power reference set to 0.2 p.u.

Fig. 9 shows the reactive power reference value and the measured reactive power output of the WF when the WF reactive power references are set to 0.1 and 0.2 p.u. . The difference between the reactive power reference and the measured value is small (less than 0.001 p.u.), which is caused by the reactive power losses inside the WF. The results show that the proposed DORPC scheme can efficiently track the reactive power reference value in a distributed manner.
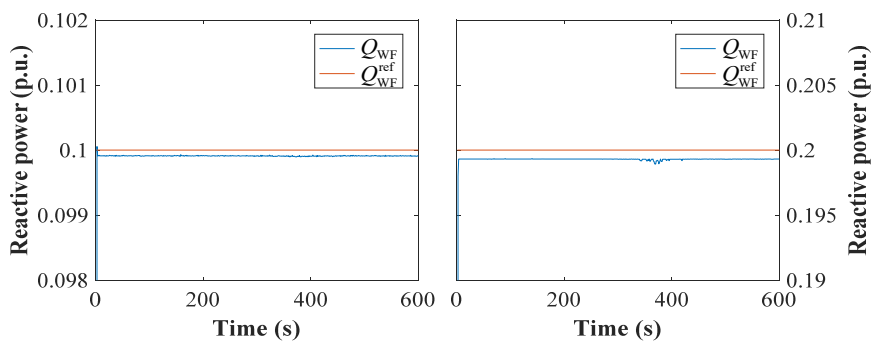

Fig. 9. Reactive power output of WF, with $Q_{\mathrm{WF}}^{\text {ref }}=0.1$ p.u. (left) and $Q_{\mathrm{WF}}^{\text {ref }}=0.2$ p.u. (right).

Figs. 10 to 15 and Table II show the losses of the total WF, network, DFIG copper, and converters and the loss reduced percentage when the WF reactive power references are set to 0.1 and 0.2 p.u. .

In Fig. 10, the reactive power reference for the WF is set to 0.1 p.u. . In Fig. 11, the reactive power reference for the WF is set to 0.2 p.u. . The total WF loss obtained using the DORPC scheme is noticeably lower than those acquired by the other two strategies, indicating that the proposed DORPC is effective in minimizing the total losses generated by the WF. In addition, the loss reduction when the reactive power reference of the WF is set to 0.1 p.u. is lower than that at 0.2 p.u., which illustrates that the higher the reactive power reference of the WF, the greater the total loss reduction.

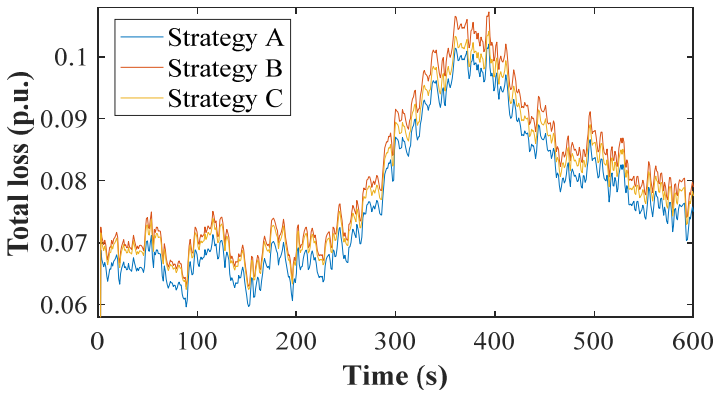






Fig. 11. Total losses of WF controlled by different strategies when reactive power reference of WF is 0.2 p.u.

Fig. 12 shows the percentage of the reduced total losses inside the WF with Strategy A when the reactive power reference of the WF is set to 0.2 p.u. Compared to Strategy B, the total power losses with the Strategy A are reduced by around $11 \%$. Compared to Strategy C, the power losses with the strategy A is reduced by around 7\% from $0 \mathrm{~s}$ to $250 \mathrm{~s}$. From $250 \mathrm{~s}$ to $360 \mathrm{~s}$, the percentage reduced decreases to around $4 \%$. From $360 \mathrm{~s}$ to $600 \mathrm{~s}$, the percentage reduced increases to around $6.5 \%$ gradually.

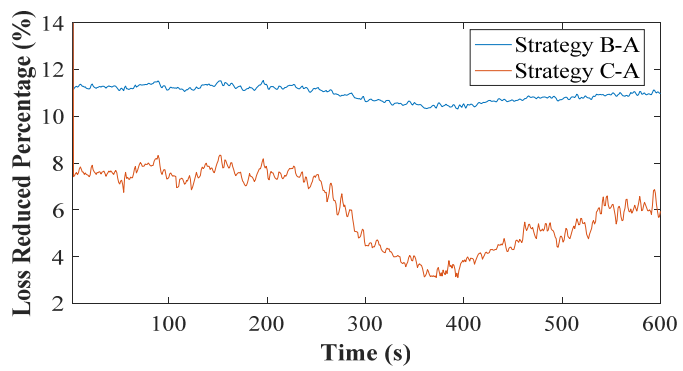

Fig. 12. Percentage of loss decrease for the WF with Strategy A when $Q_{\mathrm{WF}}^{\text {ref }}$ is 0.2 p.u. .

Table II shows power losses of the WF at different time with different control strategies. The first row shows the average power losses during the whole simulation time. Strategy A has the lowest power losses in the WTs. The network loss with Strategy A is approximately equal to those with Strategy C. For the total losses inside the WF, Strategy A shows the superiority among the three strategies. The 2-6th rows are the power losses at different simulation time. The WF with the strategy A generates the lowest power losses of WTs among the three strategies. The network losses with Strategy A and Strategy C are similar, which are better than those with Strategy B. For the total losses inside the WF, Strategy A shows the superiority among the three strategies at each measurement point.

TABLE II

LOSSES OF DIFFERENT PARTS IN THE WF WITH DIFFERENT CONTROL STRATEGIES

\begin{tabular}{l|lll|llll|lll}
\hline \hline \multirow{2}{*}{$\begin{array}{l}\text { Different simulation } \\
\text { time points }\end{array}$} & \multicolumn{5}{|l|}{ Power losses in the WTs (p.u.) } & \multicolumn{4}{l|}{ Network losses (p.u.) } & \multicolumn{3}{l}{ Total power losses (p.u.) } \\
\cline { 2 - 10 } & A & B & C & A & B & C & A & B & C \\
\hline Average power loss & 0.0248 & 0.0254 & 0.0300 & 0.0529 & 0.0618 & 0.0525 & 0.0777 & 0.0872 & 0.0825 \\
Power loss at 100s & 0.0215 & 0.0221 & 0.0275 & 0.0458 & 0.0537 & 0.0453 & 0.0673 & 0.0758 & 0.0728 \\
Power loss at 250s & 0.0216 & 0.0223 & 0.0276 & 0.0463 & 0.0542 & 0.0458 & 0.0679 & 0.0765 & 0.0734 \\
Power loss at 320s & 0.0278 & 0.0285 & 0.0321 & 0.0594 & 0.0692 & 0.0591 & 0.0872 & 0.0977 & 0.0912 \\
Power loss at 380s & 0.0317 & 0.0324 & 0.0351 & 0.0677 & 0.0787 & 0.0677 & 0.0994 & 0.1110 & 0.1028 \\
Power loss at 500s & 0.0268 & 0.0275 & 0.0315 & 0.0575 & 0.0670 & 0.0571 & 0.0844 & 0.0945 & 0.0886 \\
\hline \hline
\end{tabular}

To better demonstrate the benefits of the DORPC, the losses in each component in the WF with different control strategies and different reactive power references are placed in Figs. 13 to 15.

Fig. 13 shows the copper losses generated by all DFIG-based WTs inside the WF. The total DFIG copper losses with Strategy A 
are less than those with Strategies B and C. If the WF only minimizes the network losses, the DFIG copper losses will increase.
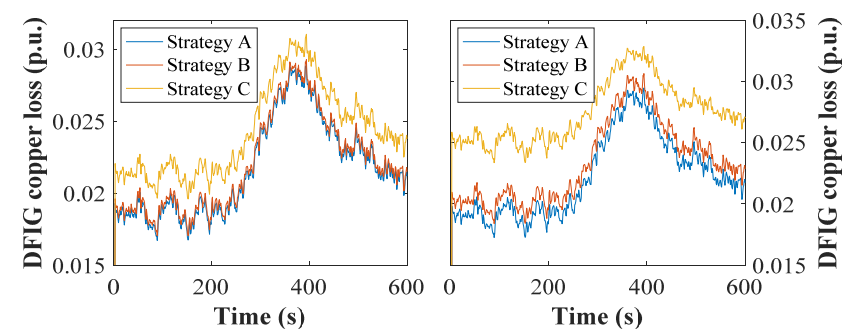

Fig. 13. Copper loss of DFIG-based WTs, with $Q_{\mathrm{WF}}^{\text {ref }}=0.1$ p.u. (left) and $Q_{\mathrm{WF}}^{\text {ref }}=0.2$ p.u. (right).

Fig. 14 shows the total converter losses inside the WF. The performance with Strategy B is better than that with the two other strategies, and the performance with Strategy A is better than that with Strategy C.


Fig. 14. Converters loss in DFIG-based WTs, with $Q_{\mathrm{WF}}^{\text {ref }}=0.1$ p.u. to the left, $Q_{\mathrm{WF}}^{\text {ref }}=0.2$ p.u. to the right.

Fig. 15 shows the loss generated by the network. The effects of Strategies A and C on reducing the loss of network are similar, that is, both are greater than the effect of Strategy B. From the above simulation results, the performance of the proposed DORPC strategy is validated. Since the DORPC considers different devices that cause losses in a WF, it can efficiently reduce the total losses of the WF and show a better performance than the two other strategies.
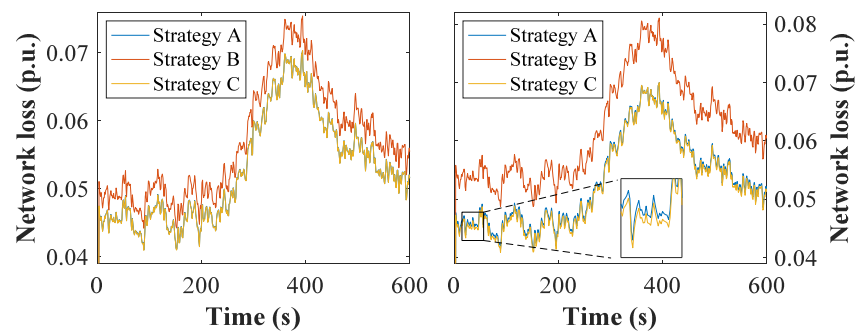

Fig. 15. Network loss in WF, with $Q_{\mathrm{WF}}^{\text {ref }}=0.1$ p.u. (left) and $Q_{\mathrm{WF}}^{\text {ref }}=0.2$ p.u. (right).

To better demonstrate the effectiveness of the DORPC, the performance of the DORPC is evaluated in Figs. 16-19 under different conditions, such as low-voltage faults, high and low wind speed scenarios.

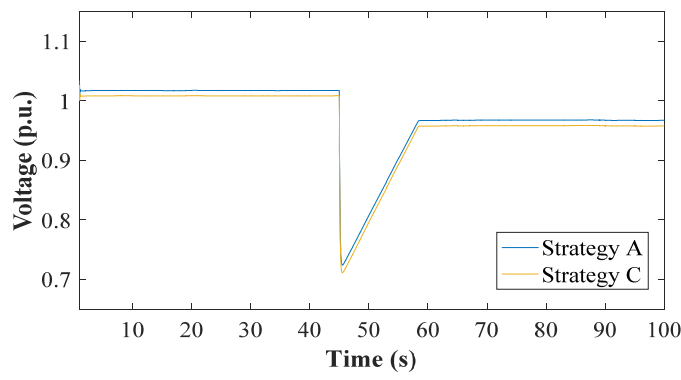


Fig. 16 shows the voltage of the MV bus of the WF. The voltage performance with Strategy A is compared to the one with Strategy C. At $45 \mathrm{~s}$, the voltage of the slack bus drops to 0.7 p.u.. The voltage of the MV bus recovers to around 0.96 p.u. from $45 \mathrm{~s}$ to $62 \mathrm{~s}$. The voltage of the MV bus can be kept within the feasible range by using both Strategy A and Strategy C.

Fig. 17 shows the total losses of the WF with Strategy A and Strategy C under the low-voltage fault. From 0-45 s, the total power losses with strategy A are less than the ones with Strategy C. At $45 \mathrm{~s}$, the losses increase to around 0.105 p.u. with the voltage drop. After $45 \mathrm{~s}$, the losses recover to around 0.07 p.u.. The total power losses with strategy A are lower than the ones with Strategy $\mathrm{C}$ during the whole simulation time. The proposed control strategy performs well during the low-voltage fault.



Fig. 17. Total losses of WF under low-voltage fault.

The total losses with different strategies under high and low wind speed scenarios are shown in Figs. 18 to 19. Fig. 18 shows the available wind power and the total losses with different strategies under the high wind speed scenario while Fig. 19 shows the ones under the low wind speed scenario. In the case of the high wind speed scenario, the available wind power fluctuates between $85 \mathrm{MW}$ and $95 \mathrm{MW}$, and the available wind power fluctuates between $48 \mathrm{MW}$ and $55 \mathrm{MW}$ in the case of low wind speed. The total losses with Strategy A are always the lowest among the three strategies under both low and high wind speed scenarios.

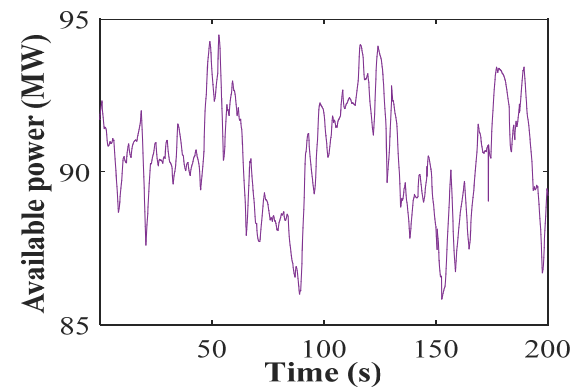

(a)

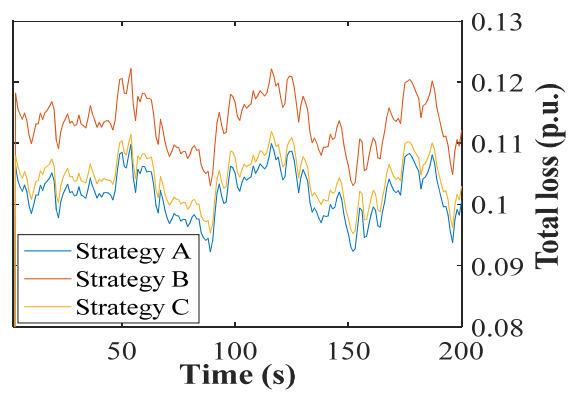

(b)

Fig. 18. Total losses with different strategies under high wind speed scenario.

(a) Available wind power, (b) total losses.

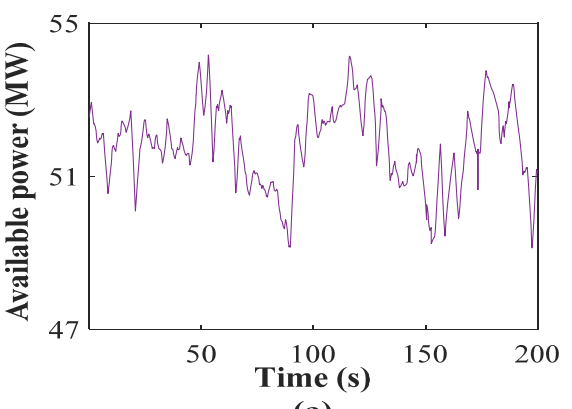

(a)

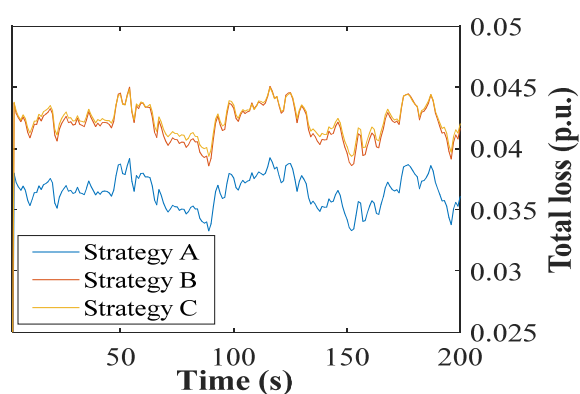

(b)

Fig. 19. Total losses with different strategies under low wind speed scenario.

(a) Available wind power, (b) total losses. 
In this paper, a DORPC scheme is proposed for loss minimization of the DFIG-based WF. The optimal control problem is formulated based on the OPF model, which is achieved by the optimal coordination of the DFIG stator and the GSC reactive power output. The optimization problem also considers the reactive power limit of WTs and feasible voltage range. The optimal control problem is solved in a distributed manner by the consensus ADMM. All controllers compute in parallel without any global information and only with the information from the neighboring controller to obtain the optimal value of the local variables. As verified by the case studies, the DORPC scheme can efficiently reduce the total WF losses while tracking the reactive power dispatch command from the TSO.

\section{References}

[1] Wang Z, Shen C, Liu F, Wang J, Wu X. An adjustable chance-constrained approach for flexible ramping capacity allocation. IEEE Trans Sustain Energy 2018; 9(4): 1798-1811.

[2] Chen R, Wu W, Sun H, Hu Y, Zhang B. Supplemental control for enhancing primary frequency response of DFIG-based wind farm considering security of wind turbines. In: Proc. 2014 IEEE PES General Meeting \& Exposition, National Harbor, USA: 2014. pp. 1-5.

[3] Duan R, Wang F, Ling Z, Jin Z. Dynamic optimal reactive power compensation control strategy in wind farms of DFIG. In: Proc. 2013 IEEE PES General Meeting, British Columbia, Canada; 2013. pp. 1-5.

[4] Tapia G, Tapia A, Ostolaza JX. Proportional integral regulator-based approach to wind farm reactive power management for secondary voltage control. IEEE Trans Energy Convers 2007; 22(2): 488-498.

[5] Karthikeya BR, Schutt RJ. Overview of wind park control strategies. IEEE Trans Sustain Energy 2014; 5: 416-422.

[6] Ullah NR, Bhattacharya K, Thiringer T. Wind farms as reactive power ancillary service providers - technical and economic issues. IEEE Trans Energy Convers 2009; 24(3): 661-672.

[7] Qiao W, Harley RG, Venayagamoorthy GK. Coordinated reactive power control of a large wind farm and a STATCOM using heuristic dynamic programming. IEEE Trans Energy Convers 2009; 24(2): 493-503.

[8] Tanaka T, Ma K, Wang H, Blaabjerg F. Asymmetrical reactive power capability of modular multilevel cascade converter (MMCC) based STATCOMs for offshore wind farm. IEEE Trans Power Electr 2019; 34(6): 5147-5164.

[9] Tapia A, Tapia G, Ostolaza JX. Reactive power control of wind farms for voltage control applications. Renew Energy 2004; 29: 377-392.

[10] Saenz JR, Tapia A, Tapia G, Jurado F, Ostolaza X, Zubia I. Reactive power control of a wind farm through different control algorithms. In: Proc. 4th IEEE Int. Conf. Power Electron. Drive Syst., Denpasar, Indonesia; 2001, pp. 203-207.

[11] Martinez-Rojas M, Sumper A, Gomis-Bellmunt O, Sudrià-Andreu A. Reactive power dispatch in wind farms using particle swarm optimization technique and feasible solutions search. Appl Energy 2011; 88(12): 4678-4686.

[12] Schönleber K, Collados C, Pinto RT, Ratés-Palau S, Gomis-Bellmunt O. Optimization-based reactive power control in HVDC- connected wind power plants. Renew Energy 2017; 109: 500-509.

[13] Guo Y, Gao H, Q. Wu, H. Zhao, Østergaard J. Coordinated voltage control scheme for VSC-HVDC connected wind power plants. IET Renew Power Gener 2018; 12(2): 198-206.

[14] Guo Y, Gao H, Wu Q, Zhao H, Østergaard J, Shahidehpour M. Enhanced voltage control of VSC-HVDC connected offshore wind farms based on model predictive control. IEEE Trans Sustain Energy 2018; 9(1): 474-487.

[15] Zhang B, Hu W, Hou P, Chen Z. Reactive power dispatch for loss minimization of a doubly fed induction generator based wind farm. In: Proc. IEEE 17th Int. Conf. Elect. Mach. Syst., Hangzhou, China; 2014, pp. 1373-1378.

[16] Zhang B, Hou P, Hu W, Soltani M, Chen C, Chen Z. A reactive power dispatch strategy with loss minimization for a DFIG-based wind farm. IEEE Trans Sustain Energy 2016; 7(3): 914-923. 
[17] Molzahn DK, Dörfler F, Sandberg H, Low SH, Chakrabarti S, Baldick R, Lavaei J. A Survey of Distributed Optimization and Control Algorithms for Electric Power Systems. IEEE Trans Smart Grid 2017; 8(6): 2941-2962.

[18] Šulc P, Backhaus S, Chertkov M. Optimal distributed control of reactive power via the alternating direction method of multipliers. IEEE Trans Energy Convers 2014; 29(4): 968-977.

[19] Guo Y, Gao H, Xing H, Wu Q, Lin Z. Decentralized Coordinated Voltage Control for VSC-HVDC Connected Wind Farms Based on ADMM. IEEE Trans Sustain Energy 2019; 10(2): 800-810.

[20] Huang S, Wu Q, Guo Y, Chen X, Zhou B, Li C. Distributed Voltage Control based ADMM for Large-Scale Wind Farm Cluster connected to VSC-HVDC. IEEE Trans on Sustain Energy. doi: 10.1109/TSTE.2019.2898102

[21] Guo Y, Gao H, Wu Q. Distributed cooperative voltage control of wind farms based on consensus protocol. Int J Electr Power Energy Syst 2019; 104: 593-602.

[22] Guo Y, Gao H, Wu Q, Østergaard J, Yu D, Shahidehpour M. Distributed coordinated active and reactive power control of wind farms based on model predictive control. Int J Electr Power Energy Syst 2019; 104: 78-88.

[23] Baran M, Wu F. Network reconfiguration in distribution systems for loss reduction and load balancing. IEEE Trans Power Del 1989; 4(2): 1401-1407.

[24] Qu L, Wei Q. Constant power control of DFIG wind turbines with super capacitor energy storage. IEEE Trans Ind Appl 2011; 47(1): 359-367.

[25] Abad G, Lopez J, Rodriguez M, Marroyo L, Iwanski G. Dynamic modeling of the doubly fed induction machine: modeling and control for wind energy generation. Hoboken, NJ, USA: Wiley, 2011. 